\title{
Repeated painful stimuli may affect pain response in neonates of more than 34 weeks post-conceptional age: A case control study
}

\author{
Astha Agarwal ${ }^{1}$, *Navratan Kumar Gupta ${ }^{2}$, Rajesh Chaudhary ${ }^{2}$, Amit Upadhyay ${ }^{2}$, Archana Dubey $^{1}$
}

Sri Lanka Journal of Child Health, 2019; 48(3): 251-255

\begin{abstract}
Objective: To evaluate the effect of repeated painful stimuli on pain response in neonates of more than 34 weeks post conceptional age.
\end{abstract}

Method: A case control study was done. Cases comprised neonates more than 34 weeks gestational age having more than ten repeated painful procedures. Controls included age and sex matched neonates with less than three painful procedures. The outcome variables were the duration of cry and Modified Facial Coding Score (MFCS) after intramuscular injection.

Results: A total of 100 neonates were enrolled (50 as cases and 50 as controls). Median (interquartile range) of duration of cry in case and control groups was 26 (20-48 seconds) and 30.5 (20-78 seconds) respectively ( $\mathrm{p}>0.05)$. MFCS score at immediate, 1 and 3 minutes was not statistically significant in the two groups $(\mathrm{p}>0.05)$.

Conclusions: Exposure to frequent painful stimuli in early neonatal life may not significantly alter pain response in neonates more than 34 weeks post conceptional age.

DOI: http://dx.doi.org/10.4038/sljch.v48i3.8761

(Keywords: Duration of cry, intramuscular injection, modified facial coding score, neonate, pain)

\section{Introduction}

Various studies have established that the pathways for pain perception are functional from early fetal life, but this neural system is still immature at birth $^{1}$. During this period of immaturity, neonates

\footnotetext{
${ }^{1}$ Subharti Medical College, Meerut, India, ${ }^{2}$ L.L.R.M Medical College, Meerut, India,

*Correspondence:navratankumargupta@gmail.com

(iD)

orcid.org/ 0000-0001-9146-3702
}

(Received on 25 November 2018: Accepted after revision on 18 January 2019)

The authors declare that there are no conflicts of interest

Personal funding was used for the project.

Open Access Article published under the Creative

Commons Attribution CC-BY (cc) (i) are exposed to repetitive painful stimuli in the form of heel lances, venipuncture, insertion of nasogastric tubes, suction etc. Exposure to such painful stimuli may potentially alter the subsequent response to pain in neonates ${ }^{2-6}$. Attenuated pain response due to habituation ${ }^{7}$ or exaggerated pain response ${ }^{8}$ have been reported. Various studies have reported that exposure to acute pain during the neonatal period causes exaggerated pain responses for a period more than what is required for the complete healing of the initial tissue injury ${ }^{9-15}$.

\section{Objectives}

This study was designed to test the hypothesis that infants of more than 34 weeks of gestation who are exposed to repeated painful stimuli demonstrate an exaggerated response to intramuscular Hepatitis-B vaccination.

\section{Method}

Study design and Setting: Hospital based case control study conducted in the neonatal intensive care unit (NICU) of Department of Pediatrics, LLRM Medical College, Meerut, India. Before carrying out this study, approval was obtained from the Institutional Ethics committee (IEC).

Participants/Inclusion criteria: Cases comprised neonates of $>34$ weeks of post-conceptional age, who had undergone more than ten painful procedures during NICU stay. Controls comprised neonates of comparable sex, gestational age and postnatal age of within one week ( \pm 7 days), who were exposed to less than three painful stimuli.

Exclusion criteria: All neonates with birth asphyxia (Apgar $<5$ at 5 minute) or delayed cry ( $>5 \mathrm{~min}$ ) if born at home, major congenital anomalies, obvious neurological abnormality, temperature $>100^{\circ} \mathrm{C}$ at the time of vaccination and birth weight $<10$ th percentile for gestational age.

Procedure: The eligible neonates admitted to NICU were categorized into cases and controls according to the number of painful stimuli experienced by them. Before enrollment, written informed consent was obtained from all the parents of neonates. The neonate's gestational age, behavioural state and details of name, age, sex and weight were recorded on a pre-structured proforma. These neonates were followed up for the number of painful stimuli they received. At the time of 
discharge, the neonates were brought to the quiet room where Hepatitis $B$ vaccination was to be done. Hepatitis B vaccine was used as a pain inducing procedure and the pain response of the cases group was compared with neonates of control group. Before vaccination, it was ensured that all enrolled babies had been fed within the last 3 hours but had not received a feed in the last 30 minutes. Two observers (NG \& RC) then came into the immunization room. ' $\mathrm{NG}$ ' administered intramuscular injection of $0.5 \mathrm{ml}$ of Hepatitis B vaccine (Revac B), using a $2 \mathrm{ml}$ syringe with a 23 gauge 1 inch length needle (Safeway company) at 90 degree angle on the anterolateral aspect of thigh (left/right) after cleaning the skin with an alcohol swab. For giving vaccine, baby was made to lie supine in mother's lap, with the thigh exposed. Rubbing the immunization site after administration was avoided. Small amount of bleeding at the injection site following vaccination was wiped gently with dry cotton. During this procedure, 'NG' called "in" when he inserted the needle and "out" when he removed the needle. This entire vaccination procedure was recorded by ' $R C$ ' on digital video camera (model Sony CCD-TRV238E) beginning 5 seconds before the vaccine was administered and continuing till 3 minutes after removal of needle. Third observer (AU) who did not know who were the cases and who were the controls and was thus blinded, analysed the outcome variables from the video recording. All three observers $\mathrm{NG}, \mathrm{RC}$ and $\mathrm{AU}$ were the same throughout the study and performed the same role in all the enrolled babies.

Assessment of outcome variables:

A. Primary outcome variable was the duration of cry (in seconds) after vaccination. It was defined as duration of continuous distressed vocalization (cry) after needle insertion to the period of silence of more than 5 seconds, excluding these 5 seconds. As video recording was done only for 3 minutes, in the babies who were still crying even after 3 minutes, the duration of cry was scored as 180 seconds only.

B. Secondary outcome variable was Modified Neonatal Facial Coding Score $(\mathrm{MFCS})^{16}$. The
MFCS was calculated immediately and after 1 and 3 minutes of needle insertion. This was a composite score obtained from the sum of the following: brow bulge, eye squeeze, nasolabial furrow, open mouth, chin quiver, and trunk movement. Each parameter was scored " 0 " if absent and " 1 " if present and the total score was obtained. One observer (AU) was responsible for giving the scores in all the babies.

In order to avoid the findings being confounded by other pain relieving methods, the following steps were ensured. All enrolled babies had been fed within the last 3 hours but had not received a feed in the last 30 minutes. The mothers were allowed to hold, talk to, or rock the baby during the procedure in all the groups. Since the state of wakefulness could have modified the response, the procedure was done in awake babies who were not crying. If baby was sleeping, he was gently awakened; if he cried, he was soothed to quiet wakefulness before the procedure. Non-nutritive sucking was not done during the procedure. All the tests were performed between 10 am to $1 \mathrm{pm}$ to avoid diurnal variation in pain response.

Sample Size: Duration of cry was the primary outcome variable and sample size was calculated on this variable. In this study 50 cases in each group were required to attain a power of $80 \%$ with test significance of 0.05 . Sample size calculation was done on the basis of pilot observation on 20 babies in this study.

Statistical analysis: Results were analysed using STATA 9.1 software. Analysis of continuous data was done with student t-test (in normally distributed data)/ Mann Whitney test (in nonnormally distributed data) and categorical variable by Chi-square test as applicable.

\section{Results}

A total of 100 neonates were enrolled (50 neonates as cases and 50 as controls). The postnatal age, sex ratio, number of painful procedure, time to last feed and duration of needle insertion was comparable in two groups (Table 1).

Table1: Base line characteristics

\begin{tabular}{|l|c|c|c|}
\hline \multicolumn{1}{|c|}{ Parameter } & Cases $(\boldsymbol{n}=\mathbf{5 0})$ & Controls $(\boldsymbol{n}=\mathbf{5 0})$ & p value \\
\hline Post conceptional age in weeks - Mean (SD) & $35.6(1.2)$ & $37.2(2.1)$ & $>0.05$ \\
\hline Postnatal age in days - Median (IQR) & $8(3-20)$ & $7.5(3-18)$ & $>0.05$ \\
\hline Weight in kg - Mean (SD) & $2.27(0.41)$ & $2.67(0.47)$ & $>0.05$ \\
\hline Male sex - Number (\%) & $27(54)$ & $25(50)$ & $>0.05$ \\
\hline Time since last feed in minutes - Mean (SD) & $45(8.2)$ & $49(4.3)$ & $>0.05$ \\
\hline Duration of needle insertion in seconds - Mean (SD) & $2.9(0.6)$ & $3.0(0.5)$ & $>0.05$ \\
\hline
\end{tabular}

SD: Standard deviation, IQR: Interquartile range

A. Primary outcome (Duration of cry): Median (interquartile range) was not significantly different in cases [26 (20-48) seconds] and controls [30.5 (20-78) seconds] $(\mathrm{p}>0.05)]$ (Figure 1$)$. 


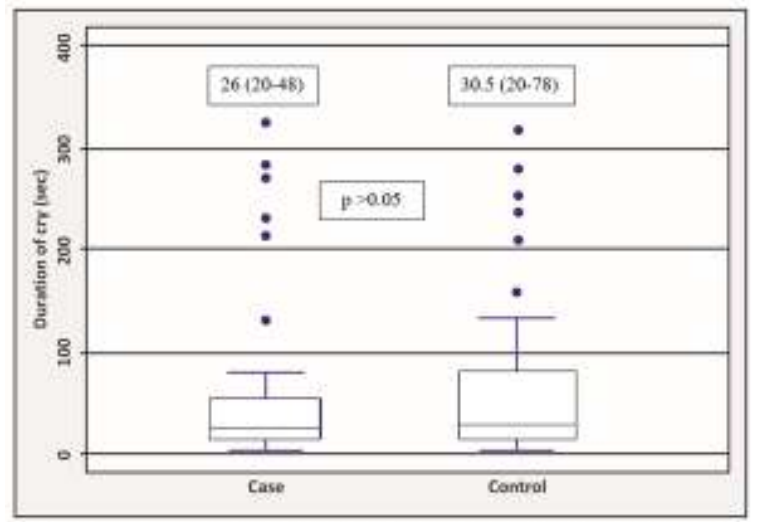

Figure 1: Duration of cry: Box and whisker plot, showing median (central line in box), inter-quartile range (horizontal limit lines of box), minimum \& maximum range (the 2 horizontal lines outside the boxes) and outliers

B. Secondary outcomes (Modified Facial Coding Score $\{M F C S\})$ : There was no significant difference in MFCS immediately, at 1 minute and 3 minutes after needle insertion in both groups ( $\mathrm{p}$ $>0.05$ ). Outcome measures are shown in Table 2.

Table 2: Outcomes measures

\begin{tabular}{|l|c|c|c|}
\hline \multicolumn{1}{|c|}{ Outcomes } & Case $(\boldsymbol{n}=\mathbf{5 0})$ & Control $(\boldsymbol{n}=\mathbf{5 0})$ & p value \\
\hline Duration of cry-Median (IQR) & $26(20-48)$ & $30.5(20-78)$ & $\mathrm{p}>0.05$ \\
\hline MFCS-Mean (SD) & & & \\
Immediate & $5.76(1.55)$ & $5.26(1.19)$ & $\mathrm{p}>0.05$ \\
After 1 minute & $1.40(2.19)$ & $1.06(1.99)$ & $\mathrm{p}>0.05$ \\
After 3 minute & $0.88(1.80)$ & $0.66(1.50)$ & $\mathrm{p}>0.05$ \\
\hline
\end{tabular}

MFCS: Modified Facial Coding Score, SD: Standard deviation, IQR: Interquartile range

\section{Discussion}

Our study demonstrated that term and near term babies with exposure to repeated painful stimuli did not show alteration in pain response to intramuscular injection. It did not demonstrate any significant difference in the duration of cry and MFCS in both groups. Similar findings were shown previously by Oberlander et al who measured facial behavioral and cardiac autonomic reactivity in former extremely low birth weight infants and compared them with term born infants ${ }^{12}$. They concluded that overall behavioral pain responses were similar between the two groups ${ }^{12}$. Peter et al also did not demonstrate difference in pain response to vaccination in toddlers with prior exposure to major surgery ${ }^{17}$. However, others have demonstrated change in response to pain after exposure to previous painful stimuli. Taddio et al demonstrated that previous pain exposure decreases the pain threshold and the infants show a greater response to subsequent painful stimuli ${ }^{8,13}$. Grunau et al studied infants under $1500 \mathrm{~g}$ who underwent heel lance and demonstrated that early pain exposure at very low gestational age exaggerates the pain response ${ }^{18}$. Johnston et al studied the effect of admission to NICU in initial weeks of life, on pain response in infants up to 32 weeks gestation.
They demonstrated that infants who were exposed to multiple painful procedures were less mature in their pain responses ${ }^{19}$. Hatfield LA et al asserts that inadequate relief of infant pain and distress during tissue-damaging procedures may permanently decrease an individual's pain tolerance, and increase pain responses later in life ${ }^{20}$.

Strengths of our study are that all observers were the same throughout the study and the person analysing the video was blind to infant group assignment. A limitation of our study could be that it only assessed the behavioral response to pain and did not assess the physiological parameter of pain assessment (heart rate, respiratory rate, oxygen saturation). We avoided use of physiological parameters because pulse oximeters often do not give readings in the crying and vigorous baby and attaching chest leads to healthy babies in procedure rooms can be intimidating and stressful to parents.

\section{Conclusions}

Exposure to frequent painful stimuli in early neonatal period may not alter pain response in neonates of more than 34 weeks post-conceptional age. 


\section{References}

1. Fitzgerald M, Anand KJS. Developmental neuroanatomy and neurophysiology of pain. In: Schechter NL, Berde CB, Yaster M, eds. Pain in Infants, Children and Adolescents. Baltimore, MD: Williams \& Wilkins; 1993:11-31.

2. Dickenson AH, Rahman W. Mechanisms of chronic pain and the developing nervous system. In: McGrath PJ, Finley A, eds. Chronic and Recurrent Pain in Children and Adolescent. Vol 13. Seattle, WA: IASP Press; 1999:5-38.

3. Ruda MA, Ling QD, Hohmann AG, Peng YB, Tachibana T. Altered nociceptive neuronal circuits after neonatal peripheral inflammation. Science 2000; 289:628-31.

https://doi.org/10.1126/science.289.5479.628

PMid: 10915627

4. Reynolds ML, Fitzgerald M. Long-term sensory hyper-innervation following neonatal skin wounds. Journal of Comparative Neurology 1995; 358(4):487-98.

https://doi.org/10.1002/cne.903580403

PMid: 7593744

5. Anand KJ, Scalzo FM. Can adverse neonatal experiences alter brain development and subsequent behaviour? Biology of the Neonate 2000; 77(2):69-8.

https://doi.org/10.1159/000014197

PMid: 10657682

6. Taddio A, Katz J. The effects of early pain experience in neonates on pain responses in infancy and childhood. Paediatric Drugs 2005; 7(4):245-57.

https://doi.org/10.2165/00148581-20050704000004

PMid: 16117561

7. Johnston CC, Stevens BJ, Franck LS, Jack A, Stremler RL, Platt R. Factors explaining lack of response to tissue damage in preterm neonates. Journal of Obstetric, Gynecologic \& Neonatal Nursing 1999; 28(6): 587-94. https://doi.org/10.1111/j.15526909.1999.tb021 67.x

8. Taddio A, Shah V, Gilbert-MacLeod C, Katz J. Conditioning and hyperalgesia in newborns exposed to repeated heel lances. Journal of the American Medical Association 2002; 288:85761.

https://doi.org/10.1001/jama.288.7.857

PMid: 12186603
9. Andrews KA, Desai D, Dhillon HK, Wilcox DT, Fitzgerald M. Abdominal sensitivity in the first year of life: comparison of infants with and without prenatally diagnosed unilateral hydronephrosis. Pain 2002; 100:35-46. https://doi.org/10.1016/S0304-3959(02)002889

10. Fitzgerald M, Millard C, McIntosh N. Cutaneous hypersensitivity following peripheral tissue damage in newborn infants and its reversal with topical anaesthesia. Pain 1989; 39:31-6.

https://doi.org/10.1016/0304-3959(89)90172-3

11. Grunau RVE, Whitfield MF, Petrie JH. Children's judgements about pain at age 8-10 years: do extremely low birth weight $(<$ or $=1000 \mathrm{~g}$ ) children differ from full birth weight peers? Journal of Child Psychology and Psychiatry 1998; 39: 587-94.

https://doi.org/10.1017/S0021963098002406

PMid: 9599786

12. Oberlander TF, Grunau RVE, Whitfield MF, Fitzgerald C, Pitfield S, Saul JP. Biobehavioural pain responses in former extremely low birth weight infants at four months' corrected age. Pediatrics 2000; 105(1):e6.

https://doi.org/10.1542/peds.105.1.e6

PMid: 10617743

13. Taddio A, Katz J, Ilersich AL, Koren G. Effect of neonatal circumcision on pain response during subsequent routine vaccination. Lancet 1997; 349:599-603. https://doi.org/10.1016/S0140-6736(96)103160

14. Taylor A, Fisk NM, Glover V. Mode of delivery and subsequent stress response. Lancet 2000; 355:120. https://doi.org/10.1016/S0140-6736(99)025490

15. Taddio A, Shah V, Gilbert-MacLeod C, Katz J. Conditioning and hyperalgesia in newborns exposed to repeated heel lances. Journal of the American Medical Association 2002; 288:857-61.

https://doi.org/10.1001/jama.288.7.857

PMid: 12186603

16. Upadhyay A, Aggarwal R, Narayan S, Joshi M, Paul VK, Deorari AK. Antinociceptive effect of expressed breast milk in procedural pain in neonates. Acta Paediatrica 2004; 93(4):518-22. 
https://doi.org/10.1080/08035250410022792 PMid: 15188980

17. Peters JW, Koot HM, de Boer JB, Passchier J, Bueno-de-Mesquita JM, de Jong FH et al. Major surgery within the first 3 months of life subsequent bio-behavioral pain responses to immunization at later age: a case comparison study. Pediatrics 2003; 111(1):129-35. https://doi.org/10.1542/peds.111.1.129 PMid: 12509565

18. Grunau RE, Oberlander TF, Whitfield MF, Fitzgerald C, Lee SK. Demographic and therapeutic determinants of pain reactivity in very low birth weight neonates at 32 weeks' postconceptional age. Pediatrics 2001; 107:105-12. https://doi.org/10.1542/peds.107.1.105

PMid: 11134442

19. Johnston CC, Stevens BJ. Experience in a neonatal intensive care unit affects pain response. Pediatrics 1996; 98:925-30.

PMid: 8909487

20. Hatfield LA, Meyers MA, Messing TM. Systematic review of the effects of repeated painful procedures in infants: Is there a potential to mitigate future pain responsivity? Journal of Nursing Education and Practice 2013; 3(8): 99.

https://doi.org/10.5430/jnep.v3n8p99 